\title{
Introduction: International Educational Exchanges and the Promotion of Peace and Intercultural Understanding
}

\author{
Julie Mathews-Aydinli
}

\section{INTERNATIONAL EDUCATIONAL EXCHANGE}

International Educational Exchange is a booming business. Once an option for just a tiny, elite few, it now embraces widely different populations ranging in age, focus and countries of origin and destination. Educational exchanges now involve the movement of massive numbers of individuals around the world for varying lengths of time; some self-funded others as beneficiaries of a wide variety of private and public scholarships and grants. Exchanges are increasingly becoming a popular part of the expected university experience for undergraduate students, stereotypically characterized by the example of a single semester or academic year spent by North American students in Western Europe. ${ }^{1}$ They are also a serious option for longer-term undergraduate or graduate study for literally millions of others. ${ }^{2}$ While many may associate such international movement primarily with students coming to or from North America or Western Europe, exchanges of people for educational purposes in fact take place

J. Mathews-Aydinli $(\bowtie)$

Graduate School of Education, Bilkent University, Ankara, Turkey

(C) The Author(s) 2017

J. Mathews-Aydinli (ed.), International Education

Exchanges and Intercultural Understanding, DOI 10.1007/978-3-319-43829-0_1 
between countries in all regions of the world, ${ }^{3}$ with some of the most rapidly growing numbers being to and from countries in Asia (see e.g. Bhandarf and Lefebure 2015).

International Educational Exchange is not restricted to students at the tertiary level; it also describes the experiences of growing numbers of secondary school or gap-year students who participate in exchanges to gain short-term international experience. Moreover, students are not the only ones taking part. Educational exchanges may also constitute a valuable research or professional development opportunity for scholarsboth those seeking employment in foreign academic institutions and those conducting long- or short-term research abroad-and professionals from various fields in the public and private sectors. Stretching the concept even further, the underlying term of 'International Education' encompasses such practices as the 'franchising' of branches of universities in other countries, and efforts to 'internationalize' local universities through curricular changes, recruiting greater numbers of foreign students and faculty or opening up online courses that are accessible to students worldwide.

\section{Why THE INTEREST In INTERNATIONAL EDUCATION EXCHANGE?}

The rise in International Educational Exchange is not surprising since it naturally seems like a positive practice to engage in. Aside from the obvious economic interests that are met by such exchanges, more noble goals appear achievable as well. Intuitively, it seems logical that educational exchanges will increase participants' knowledge and understanding of others' practices and beliefs, and this will in turn contribute to better, friendlier relations between the participants and the others. This broad intuition is based on the concept of intercultural understanding and two follow-up assumptions: first, that such understanding can be improved through the kind of contact encouraged by educational exchanges and second, that the more we know about those who are different from us, the better we will get along with them. It follows that in an era when ease of travel and communication, not to mention more ominous cross-border flows such as disease, terrorism or environmental hazards, have made contact between different peoples both common and necessary, any efforts that may help build knowledge and improve understanding are essential. International Educational Exchange-in all its forms - seems logically a way of accomplishing this. 
While there may certainly be personal benefits to increased intercultural understanding, such as making someone a more effective manager in an international company or contributing to his or her enjoyment of foreign travel or literature, it again seems logical that there may also be potential benefits at the broader, societal level. If enough people in two populations are fortunate enough to gain greater intercultural understanding of the other group, or if individuals in critical political, bureaucratic or social positions from each group increase their intercultural awareness, it may reduce the likelihood of clashes between those two groups. It is this larger, societal potential that brings International Educational Exchange to the interest of those in governments, and leads to the inserting of educational exchanges onto the menu of public diplomacy tools.

\section{International Educational Exchange and Public Diplomacy}

When government officials speak of 'winning hearts and minds', they are, in essence, talking about public diplomacy. Unlike traditional diplomacy, which is conducted between high-level officials, often out of public view, and which aims to mend or build state-level relations between countries, public diplomacy takes place at a more transnational level. It seeks to build up relations between societies, and is therefore conducted with the help of everyday people or civil society groups. As one effort to conceptualize the practice of public diplomacy has concluded, its goal is to transmit information, sell positive images of a country and build long-term relationships that will help ease future government policies (Leonard et al. 2002). To this end, most American public diplomacy efforts throughout the Cold War era were devoted to international broadcasting and media to spread anti-Communist propaganda. Having been largely abandoned after the end of the Cold War, interest in public diplomacy resurged in the 2000s, as the US government scrambled for tools to bridge the apparent cultural divide that had spawned the terrorist attacks of $9 / 11$ and in subsequent years continued to supply the ranks of groups affiliated with al Qaeda or the Islamic State.

While both traditional and public diplomacy involve efforts to change others' behaviors or obtain from them particular desired outcomes, public diplomacy is associated with doing so through applying 'soft power', in other words, by looking beyond matters of military force or economic prosperity, and adding in concerns for legitimacy and moral authority (Nye 2004). It is easy to imagine how International Educational Exchanges 
might therefore play a central role in public diplomacy efforts. The primary participants in such exchanges are generally 'regular' citizens, either students or members of the scholarly community. They thus naturally present an image of legitimacy as they are removed from any immediate sense of mistrust or dislike that may be associated with a government. Their aim during an exchange program is one of education-again, a pure and positive goal that is easily distanced from the possible negative or propagandistic actions of a government. The way that exchanges are practiced and their presumed positive impact depend on a long-term, two-way process of people accumulating information about each other, understanding and digesting that information and presumably reflecting back on that understanding in future interactions with the other group. Compare this thoughtful, long-term process of building change with the doublespeak and secretive negotiating that is associated with traditional diplomatic efforts. As the early twentieth-century American journalist Isaac Goldberg is attributed with saying, 'Diplomacy is to do and say, the nastiest thing in the nicest way'. Clearly, the potential effectiveness of the 'citizen diplomats' involved in international education exchanges, who can remain distanced from this image, is tremendous.

While the match between educational exchange and public diplomacy seems a logical and practical one, it is not problem-free. The main dilemma that arises is one that is inherent to virtually all public diplomacy efforts: the clash between their 'public face' of aiming to build deeper intercultural understanding and awareness, and their underlying strategic goal of using that outcome to create an environment that will enable government policies. ${ }^{4}$ Because of this dilemma, the relationship between International Educational Exchange and public diplomacy is a sensitive one. Yet it remains one that has received relatively little scholarly attention. Even today, in an era of both increased numbers of participants in international educational exchanges and growing appreciation of the potential for such exchanges to contribute to intercultural understanding, and, thus, public diplomacy, research on the topic is limited.

\section{Overview of THE BOOK}

When considering the role of International Educational Exchange in promoting peace and intercultural understanding, what emerges is a very complex picture. A variety of factors contribute to this complexity. The chapters in this book first explore these factors and the concerns that must be considered 
when administering or initiating International Educational Exchange programs. For example, they look at the role that language and discourse play in exacerbating or alleviating the abovementioned dilemma in public diplomacy. They also preview new means of internationalizing education and their impact on public diplomacy, and explore ways of evaluating the impact-not only the challenges that assessment presents, but reasons behind the overall push for it. The book then goes on to provide additional insights by presenting several case studies of diverse educational exchange programs and one study on a program preparing students for such exchanges.

Leading off the volume is Darla Deardorff's chapter, which directly delves into the connection between International Educational Exchange and its impact on developing intercultural understanding. After revealing certain myths about the idea of exchanges and intercultural understanding, she presents the reader with a description of what Intercultural Competence ideally means, and, therefore, what educational exchanges (and, ultimately, political diplomacy) should aim to do. She identifies mutuality as a key element, thereby suggesting that if educational 'exchanges' are in practice or image one-directional, or too obviously working to the benefit of one side over the other, they will not likely be successful in the long run.

The next four chapters discuss issues that seem to pose potential risks to mutuality, and thus to having successful international educational exchanges. Iain Wilson directly explores the ways that international educational exchanges, or more generally, student mobility, are meant to help promote peace - public diplomacy's most idealistic goal-and questions to what extent they actually achieve this. He examines in detail the existing empirical research measuring the impact of educational exchange in terms of five distinct mechanisms: signaling, attitude change, intercultural competence, network formation and transfer of governmental institutions. Equally important to the conclusions he draws from this body of research are the insights he makes into the methodological and epistemological challenges surrounding such inquiries.

Will Baker goes on to look specifically at the role of language in educational exchanges. With English frequently the common language or 'lingua franca' used in international education, it has the potential to serve as a positive means for communication among people of diverse linguistic and cultural backgrounds. It also runs the risk, however, of creating the linguistic and cultural imperialism that is reflected in the chapter's title'lingua frankensteinia'. ${ }^{5}$ Baker argues that for educational exchanges to 
achieve their ultimate goals, efforts must be made to ensure that the ideological issues surrounding the use of English are not ignored, and that alternative approaches to language education be applied.

Craig Hayden's chapter looks more deeply at the issue of technology, and the potential of Massive Open Online Courses, or MOOCs, to promote the positive side of public diplomacy efforts. He suggests that by providing genuine open access to the benefits of international education, MOOCs may have the potential to counteract some of public diplomacy's more negative, instrumental attributes. He admits that it is still early to draw firm conclusions as much more research is needed. He also cautions of the risk that technological innovations like MOOCs may merely shift the dilemma in public diplomacy in a new direction. Instead of a dilemma between a 'public face' of promoting real understanding and a negative undercurrent of political propaganda, we may see an emerging dilemma between public diplomacy's ideal and a new, more commercial negative side, in which the efforts constitute primarily advertising campaigns for higher education in the USA.

A somewhat similar concern is raised in Hamilton Bean's look at the discourse used in educational exchanges. Bean's chapter shows that even when the discourse itself changes, it does not necessarily mean that public diplomacy's dilemma has been overcome. He warns of the potential that what he dubs the 'marketization' discourse used by the US State Department's Bureau of Educational and Cultural Affairs when discussing initiatives like the Fulbright Program may not only reflect but even reinforce assumptions about International Educational Exchange that hinder the possibility for the 'positive' side of public diplomacy to take place.

The second half of the book highlights four empirical studies-three on existing educational exchange programs and one on a training program for students about to engage in an exchange. Carol Atkinson's study leads off this section. Among works exploring the relationship between educational exchanges and the promotion of peace, an almost completely ignored yet pivotal area to look at is the exchange involving members of the military. Atkinson's work is among the first to explore the goals and structure of educational exchanges arranged through the US military's war and staff colleges. Arguing that they have been successful in promoting increased understanding, interoperability and cooperation, she then draws lessons from this experience for the designing and administering of international educational exchanges on a broader scale. 
The following chapter, by Emily Metzgar, looks at another important type of exchange program - that of sending people abroad (or inviting them from abroad) to teach their native language. Understanding the background and conduct of such programs is of great importance, not only due to the issues about language raised in this volume by Will Baker but also because of the rising interest in recent years in efforts to use language teaching programs in public diplomacy efforts. ${ }^{6}$ One of the largest such language teaching programs worldwide is the Japan Exchange and Teaching, or JET Program. Metzgar reports on a large-scale survey study she conducted with American JET alumni, attempting to measure the program's impact on participants' attitudes toward the host cultureultimately, their levels of intercultural understanding. Based on her results, she then discusses the implications of her study's results on measuring the impact of the JET Program as a public diplomacy tool.

Yasemin Kirkgoz explores another well-known language teaching exchange program, the Fulbright Foreign Language Teaching Assistant (FLTA) Program. Taking a very different methodological approach from Metzgar, Kirkgoz also explores the attitudes of program returnees, this time Turkish FLTA participants. She conducts a series of interviews with eight Turks in the years following their time as FLTAs teaching Turkish in American universities. She explores their recalled experiences, focusing most importantly on any change in their perspectives, specifically in the areas of attitudes toward education, democracy and intercultural issues. Her conclusions regarding the experiences of these teachers support earlier similar studies conducted with students, that at least at the personal level, educational exchanges can contribute to changed attitudes and perspectives toward not only the host culture but the participants' own cultures as well.

The final chapter in the volume, by Faruk Kural and Yasemin Bayyurt, winds up the discussion on International Educational Exchange and the promotion of peace and intercultural understanding by taking a step back- to the pre-exchange preparation that students receive. Drawing on data collected from Turkish university students prior, during and following a study-abroad experience, Kural and Bayyurt design a preparatory English language training curriculum. With their data reflecting some of the concerns raised in both Baker's and Deardorff's chapters in this volume, the authors argue the need for predeparture language training that incorporates a broader, more inclusive perspective on English. The resulting curriculum not only provides more realistic and therefore 
effective English language instruction but also contributes to building the students' intercultural competence, thus supporting a more successful exchange experience at both the individual and broader societal levels.

\section{Notes}

1. Two examples evidencing this growth in exchanges can be seen in the cases of the USA and Europe. The most recent Opendoors Report shows 289,000 American students studying abroad in $2012-2013$, a $2 \%$ increase over the previous year. In total, $9 \%$ of American undergraduate students will study abroad at some time during their undergraduate studies. The Erasmus Program, which supports student and staff exchanges throughout the European Union, also has noted growing numbers of participants, with nearly 270,000 students and 52,000 staff members taking part in exchanges in the 2012-2013 academic year-up from around 3000 students when the program was launched in 1987.

2. Overall, based on 2011 data from the Organisation for Economic Cooperation and Development, the total number of internationally mobile students more than doubled between 2000 and 2011, to nearly 4.5 million, with a projection of that number reaching 5 million in 2014. Of this number, the USA is the world's leading destination. The Opendoors Report from 2014 showed that just under 900,000 international students were studying in the USA in 2012-2013.

3 . Just one example from a country that might not ordinarily be considered in such a discussion is the initiative launched in 2012 by the Turkish government. The Turkiye Scholarships Program provides scholarships to approximately 4000 foreign students each year to study at Turkish universities. Applications to the program have risen from nearly 46,000 in 2012 to over 82,000 in 2014, from 176 different countries. Overall, the number of exchange students coming to Turkey each year is rising rapidly, reaching nearly 50,000 in 2014.

4. This dilemma is discussed originally by Giles Scott-Smith, in his 2008 article, 'Mapping the undefinable: Some thoughts on the relevance of exchange programs within International Relations Theory'. Annals of the American Academy of Political and Social Science 616: 173-195. 
5. A term coined by Robert Phillipson. (2008). Lingua franca or lingua frankensteinia? English in European integration and globalisation. World Englishes, 27(2), 250-267.

6. Examples of such programs from other countries include the Chinese government's establishing in 1987 of the National Office for Teaching Chinese as a Foreign Language, Hanban, with its Confucius Institutes (CI) and Classrooms (CC) targeting higher education and K-12, respectively. As of the end of 2014, there were 475 CIs and 851 CCs worldwide. From the perspective of US public diplomacy, the Fulbright English Teaching Assistant (ETA) Program is another example of an initiative gaining interest in recent years.

\section{REFERENCES}

Bhandarf, R., \& Lefebure, A. (Eds.). (2015). Asia: The next higher education superpower. New York: IIE.

Leonard, M., Smewing, C., \& Stead, C. (2002). Public diplomacy. London: Foreign Policy Centre.

Nye, J. S. (2004). Soft power: The means to success in world politics. New York: PublicAffairs.

Phillipson, R. (2008). Lingua franca or lingua frankensteinia? English in European integration and globalisation. World Englishes, 27(2), 250-267.

Scott-Smith, G. (2008). Mapping the undefinable: Some thoughts on the relevance of exchange programs within International Relations Theory. Annals of the American Academy of Political and Social Science, 616, 173-195. 